\title{
Effectiveness of Energy Conservation Techniques in Patients with COPD
}

\author{
Ann Sylvia Louise Wingårdh ${ }^{a, d}$ Carina Göransson ${ }^{a}$ Sven Larsson ${ }^{b}$ \\ Frode Slinde $^{c}$ Lowie E.G.W. Vanfleteren ${ }^{d, e}$ \\ ${ }^{a}$ Department of Occupational Therapy and Physiotherapy, Sahlgrenska University Hospital, Gothenburg, Sweden; \\ bSahlgrenska University Hospital, Gothenburg, Sweden; 'Department of Food and Nutrition, and Sports Science, \\ University of Gothenburg, Gothenburg, Sweden; ${ }^{\mathrm{d} C O P D}$ Center, Department of Respiratory Medicine and

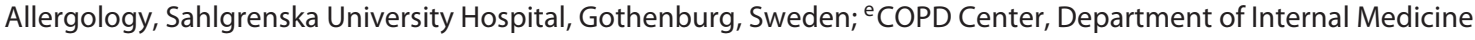 \\ and Clinical Nutrition, Institute of Medicine, Sahlgrenska Academy, University of Gothenburg, Gothenburg, Sweden
}

\section{Keywords \\ Occupational therapy · Chronic obstructive pulmonary \\ disease - Work simplification - Breathing exercises . \\ Metabolic equivalent}

\begin{abstract}
Background: Patients with chronic obstructive pulmonary disease (COPD) might suffer from severe dyspnea, which importantly impacts on the performance of activities of daily living (ADL). Patient training of energy conservation techniques (ECTs) might be useful to improve the tolerance and execution of these $A D L$, but objective studies evaluating the effect of teaching ECTs on the metabolic equivalent of task (MET) in patients with COPD are sparse. Objectives: The aim of this study was to test the hypothesis that practicing ECTs after a 2-week ECT teaching period would reduce the energy expenditure (MET) in performing an activity in patients with severe COPD. Methods: Energy expenditure was assessed with a gas exchange system (Oxycon ${ }^{\mathrm{TM}}$ Mobile) during one out of five standardized ADL before and after a 2-week intervention period in which ECTs were taught. These ECTs comprised a good breathing technique, an ergonomic way of performing the activity, and the use of assistive devices. $\boldsymbol{R e}$ -
\end{abstract}

sults: Thirty-two patients with COPD (mean FEV $1: 39 \pm 14 \%$; female: $n=18$; age: $68 \pm 7$ years) were included. A significantly lower MET $(2.3 \pm 0.6$ to $2.1 \pm 0.5 ; p<0.05)$ and less desaturation ( $89.7 \pm 5.2$ vs. $\left.91.1 \pm 5.5 \% \mathrm{HbO}_{2} ; p<0.05\right)$ were seen while performing the same activity after the intervention. However, there was no significant difference in the time spent on the task performed $(6.0 \pm 3.9$ vs. $6.7 \pm 4.0 \mathrm{~min} ; p>$ 0.05). Conclusions: A 2-week educative program on ECTs successfully reduces the energy spent for performing ADL relevant to the patient without any significant increase in the time spent on the activity.

(C) 2020 The Author(s)

Published by S. Karger AG, Basel

\section{Introduction}

Patients with severe chronic obstructive pulmonary disease (COPD) suffer from pronounced ventilatory limitation, impaired maximal oxygen uptake and energy expenditure, and related symptoms, most commonly dyspnea. These result in severe limitation of exercise capacity, which seriously affects a person's ability to perform activities of daily living (ADL). Many affected patients express the importance of being independent $[1,2]$. Being independent 


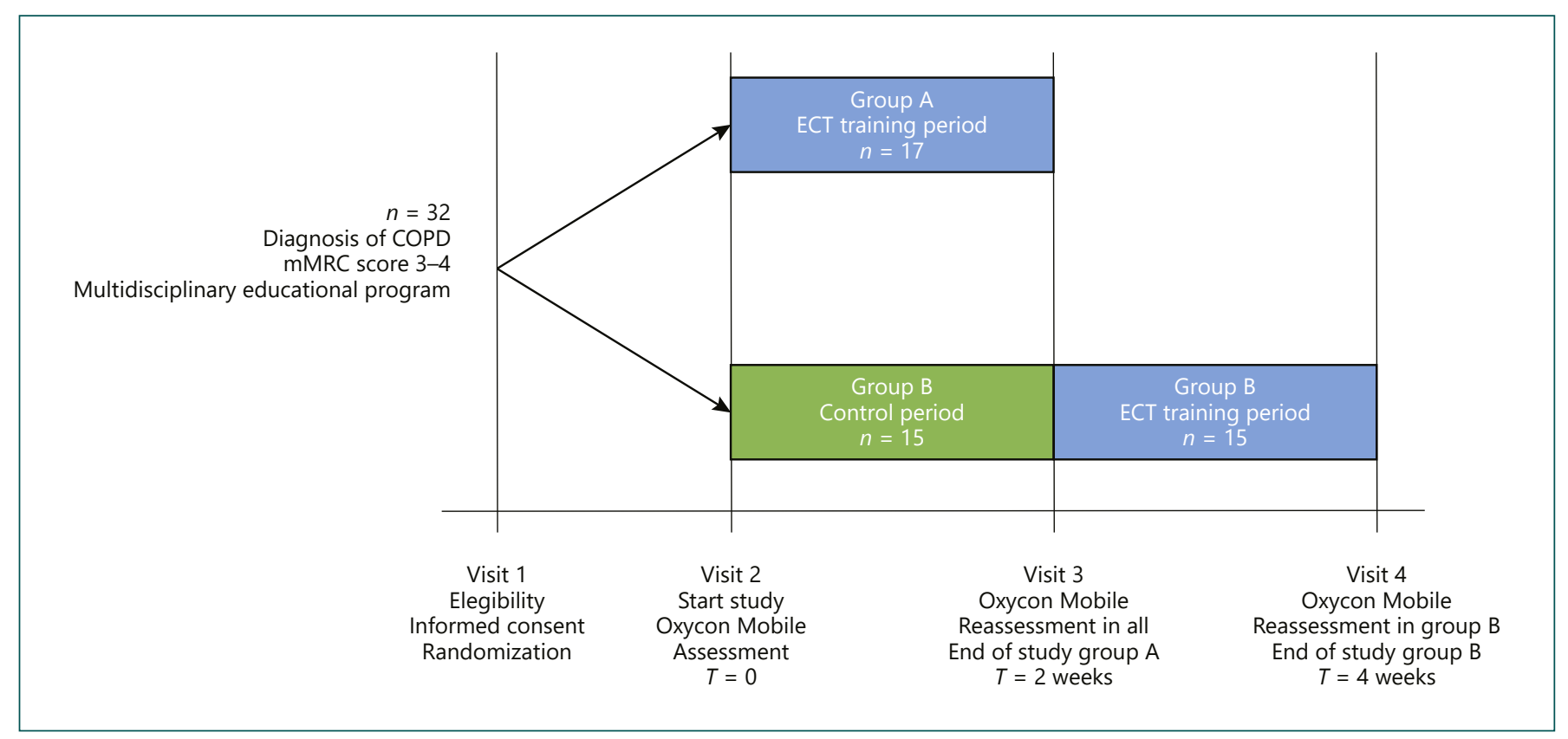

Fig. 1. Study design and flow chart. ECT, energy conservation technique; COPD, chronic obstructive pulmonary disease; mMRC, modified Medical Research Council.

imposes demands on the ability to perform several daily activities. Considering that chronic diseases like COPD are permanent and irreversible, there is a need to focus on the individual residual capacity and provide tools for enhancing functional status and minimizing distressing symptoms, which might be related to improvement in quality of life [3]. To reach these goals, an interprofessional approach is needed in order to address the complexity of care for the patient with COPD in which the occupational therapist has an essential part. Performing daily activities while spending as little energy as possible is to be recommended to these patients. The less energy spent on each activity, the more tasks patients are able to perform throughout the day [3]. Energy conservation techniques (ECTs) $[4,5]$ specifically aim at performing ADL with reduced energy expenditure. Although largely recommended, only limited data are available on the effects of ECTs on the metabolic equivalent of task (MET) during the performance of ADL in patients with COPD. Velloso and Jardim [6] showed a significantly lower oxygen uptake and dyspnea perception in COPD patients when using ECTs.

The aim of this study was therefore to test the hypothesis that a 2-week educative program on ECTs would reduce the energy (expressed as the MET) spent on performing ADL relevant to daily life for patients with severe COPD.

\section{Subjects and Methods}

\section{Participants}

Highly symptomatic (modified Medical Research Council dyspnea scale score 3-4) patients with COPD were recruited consecutively from the Department of Pulmonary Medicine, Sahlgrenska University Hospital, Gothenburg, Sweden. All of them participated in a multidisciplinary educational program for patients with COPD, of which occupational therapy was one of the components. Patients were excluded from participation if they were on oxygen treatment, unable to transfer to Sahlgrenska University Hospital, unable to collaborate, unable to talk or understand Swedish, not living at home, or not able to walk; had malignant disease not in a stable phase; suffered from clinically relevant chronic heart insufficiency, muscle disease, metabolic disease, or renal insufficiency; or had asthma as the main respiratory disease.

\section{Study Design}

After inclusion and written consent, the patients were randomized into two groups by A-and-B lottery. Group A $(n=17)$ was assessed on 2 occasions, with a training period of 2 weeks in between. Group B $(n=15)$ had a delayed intervention with a 2-week control period and reassessment prior to the intervention. Consequently, group B was assessed on 3 occasions with 2 weeks between each. This parallel study group design enabled us to ensure the validation and repeatability of the results. Figure 1 illustrates the study design and flow.

\section{Intervention}

ECTs were trained for a period of 2 weeks [7]. A detailed manual was developed to assure the consistency of the training 
for all subjects. Examples of interventions were training to use ergonomic principles, pursed lip breathing, and, if possible, diaphragmatic breathing $[8,9]$. The subjects were trained to place their equipment at chest height; they were trained to work at paced speed and in some cases instructed to use technical aids $[4,5]$. Two occupational therapists were involved who were responsible for training and evaluation, respectively. To ensure that the measurements were done without influence by the training occupational therapist, the occupational therapist left the room at the final measurement and the therapist responsible for measurement stayed.

\section{ADL Task Instruction before and after Intervention and \\ Measurement Procedure}

Before starting the ADL, chosen by the patients to be burdensome in terms of dyspnea, all patients listened to relaxing music for 10 min wearing the Oxycon Mobile device. The activities were selected according to the subject's experience of them causing dyspnea and the authors' belief that they could possibly be trained in a study setting. The five activities were the following:

\section{(1) Hang Up Laundry}

Before Intervention. Ten dry towels should be taken out of a washing machine and hung up one by one on a drying rack for laundry.

Intervention. Use the breathing technique in coordination with all movements. The patients were instructed to sit down, use a short reacher to pick the towels out of the machine and put them in a basket, place the basket on a low chair, raise the chair, and hang the laundry on an indoor foldable clothes drying rack.

(2) Make the Bed

Before Intervention. The bed to be made was placed with one side next to a wall. The sheets, pillow, blanket, and bedspread were placed on a chair beside the bed.

Intervention. Use the breathing technique in coordination with all movements. The bed was raised $10 \mathrm{~cm}$ and placed free from any walls, and a lightweight bedspread was used. The patients were instructed to avoid stretching out far away from the body while making the bed.

(3) Put On and Off Trousers, Stockings, and Shoes

Before Intervention. Big jogging pants, stockings, and shoes were placed on a bed. The patients put on and off the clothes - if possible, in a standing position.

Intervention. Use the breathing technique in coordination with all movements. The patients were instructed to sit down while dressing, use a stocking aid to put on the stockings, and use a long shoehorn.

\section{(4) Prepare an Instant Soup}

Before Intervention. The ingredients and utensils were placed on shelves higher than at shoulder height, and lower than at hip height. The patients were standing up during the activity.

Intervention. Use the breathing technique in coordination with all movements. The patients were instructed to sit down on a chair with adjustable height while preparing the soup, and the ingredients were placed at chest height.

\section{(5) Bake a Sponge Cake}

Before and after Intervention. The same conditions and strategies were used as in activity 4, but this activity was more complex, took more time, and was more challenging.

\section{Measurement and Definition of Energy Expenditure}

Energy expenditure was assessed using the Oxycon Mobile device. The Oxycon Mobile (VIASYS Healthcare, Conshohocken, PA, USA) is a battery-operated, lightweight, portable wireless metabolic system measuring gas exchange breath by breath, attached to the body in a vest system. A flow sensor unit is connected to a face mask detecting air flow by rotation of a low-resistance, bidirectional turbine; it allows determination of ventilation.

Via a sampling line connected to the flow sensor unit, the expired air is analyzed for $\mathrm{O}_{2}$ and $\mathrm{CO}_{2}$ concentrations in a sensor box using a micro fuel cell and thermal conductivity, respectively. Saturation $\left(\mathrm{SpO}_{2}\right)$ is measured with a pulse oximeter sensor attached to the forehead. A data exchange unit collects the data and sends them telemetrically to a base station connected to a computer.

After 15 min of warm-up time and immediately before data collection, a 2-point $\left(0.2\right.$ and $\left.2.0 \mathrm{~L} \mathrm{~s}^{-1}\right)$ air flow calibration was performed using the automatic flow calibrator, and the gas analyzers were calibrated against a certified gas mixture of $5 \% \mathrm{O}_{2}, 16 \% \mathrm{CO}_{2}$, and $79 \% \mathrm{~N}_{2}$ (Rießner-Gase GmbH \& Co., Lichtenfels, Germany), together with determination of the measurement delay.

Energy expenditure was calculated for the gas exchange data using the Weir equation [10]: $\mathrm{EE}(\mathrm{kJ})=4.184\left(3.9 \mathrm{VO}_{2}+1.1 \mathrm{VO}_{2}\right)$. The MET is a physiological measure expressing the energy cost of physical activities and is defined as the ratio of the metabolic rate during a specific physical activity to a reference metabolic rate, set by convention to $3.5 \mathrm{~mL} \mathrm{O} \cdot \mathrm{kg}^{-1} \cdot \mathrm{min}^{-1}$, or equivalently: when resting, the body uses 1 MET for basic functions such as breathing [11]. In this study, we measured duration of activity in minutes, saturation $\left(\mathrm{SpO}_{2} \%\right), \mathrm{VO}_{2}(\mathrm{~mL} / \mathrm{min})$, energy expenditure $(\mathrm{kJ} / \mathrm{min})$, $\mathrm{MET}$, and total energy cost of activity (kcal).

\section{Statistical Analysis}

The results are expressed as mean \pm SD unless indicated otherwise. Student's paired $t$ test was used to investigate differences in outcomes between patients in the different groups. Differences in the proportion of patients in both groups were assessed using the $\chi^{2}$ test. The results are expressed as mean \pm SD for quantitative variables and percentage for discrete variables.

\section{Results}

The study participants' flow chart is presented in Figure 2. Ninety-two patients were eligible. Of these, 38 declined to participate, 13 were excluded as screen failures, and 2 were excluded for other reasons. In total, 39 patients were included in the study and signed informed consent forms. Seven patients dropped out of the study and 32 patients completed the study. The subjects who aborted the measurements due to exertion both chose the activity "make the bed." 
Fig. 2. Flow chart of the subjects included in and excluded from the study.

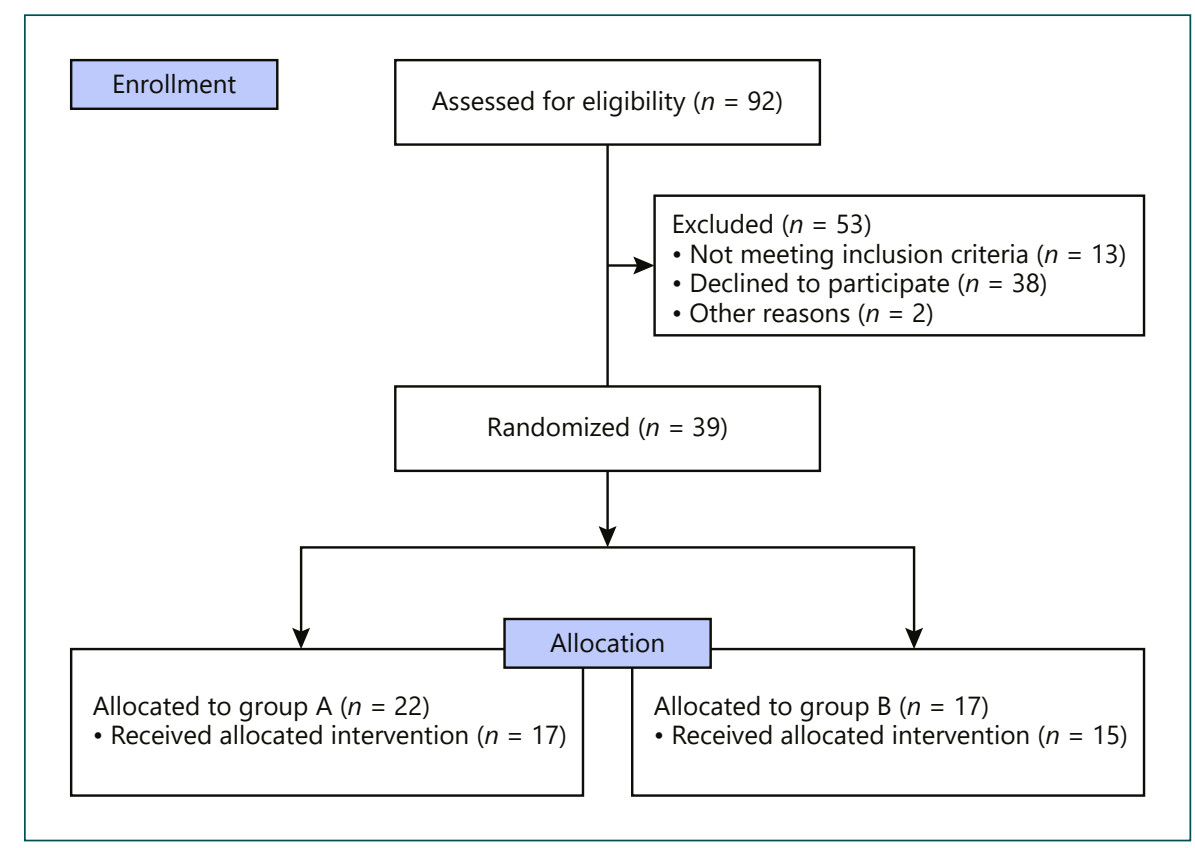

Table 1. Subject characteristics $(n=32)$

\begin{tabular}{ll}
\hline Female gender, $n(\%)$ & $18(56)$ \\
Age, years & $68 \pm 7$ \\
Height, m & $1.69 \pm 0.09$ \\
Weight, kg & $73.5 \pm 17.0$ \\
BMI, kg/m ${ }^{2}$ & $25.7 \pm 5.3$ \\
Disease severity GOLD standard & \\
FEV,$\%$ & $39 \pm 14$ \\
GOLD 1 mild $(\geq 80 \%), n$ & 0 \\
GOLD 2 moderate $(50-80 \%), n$ & 7 \\
GOLD 3 severe $(30-50 \%), n$ & 16 \\
GOLD 4 very severe $(<30 \%), n$ & 9
\end{tabular}

Values are presented as mean \pm SD unless specified otherwise. GOLD, Global Initiative for Chronic Obstructive Pulmonary Lung Disease [24]; $\mathrm{FEV}_{1}$, percentage of predicted forced expiratory volume in $1 \mathrm{~s}$.

\section{Characteristics}

The characteristics of the 32 included subjects are presented in Table 1. On average, they were elderly patients, with severe to very severe airflow limitation and a normal BMI.

\section{Chosen Activities}

All five activities were chosen, but with different frequency. "Hang up laundry" was the most frequently chosen activity (11 patients), while "bake a sponge cake" was chosen least often (2 patients). "Make the bed" and "put on and
Table 2. Results from the Oxycon ${ }^{\mathrm{TM}}$ Mobile system, control period only

\begin{tabular}{lcc}
\hline & $\begin{array}{l}\text { Before } \\
\text { control period } \\
(n=15)\end{array}$ & $\begin{array}{l}\text { Before } \\
\text { intervention } \\
(n=15)\end{array}$ \\
\hline Duration of activity, min & $5.9 \pm 4.2$ & $5.3 \pm 3.6$ \\
$\mathrm{SpO}_{2}, \%$ & $91.3 \pm 4.9$ & $91.7 \pm 5.1$ \\
$\mathrm{VO}_{2}, \mathrm{~mL} / \mathrm{min}$ & $521 \pm 160$ & $528 \pm 162$ \\
Energy expenditure, $\mathrm{kJ} / \mathrm{min}$ & $10.5 \pm 3.3$ & $10.5 \pm 3.4$ \\
$\mathrm{MET}$ & $2.2 \pm 0.6$ & $2.3 \pm 0.6$ \\
Total energy cost of activity, kJ & $62.7 \pm 46.0$ & $55.7 \pm 37.2$ \\
\hline
\end{tabular}

Values are presented as mean \pm SD. MET, metabolic equivalent of task.

off trousers, stockings, and shoes" were both chosen 8 times. Three patients made instant soup (Fig. 3). No one indicated problems when choosing an activity from the five suggested. The patients who aborted the measurements due to exertion both chose to make the bed. No significant difference in gender was seen in the choice of activity.

\section{Reproducibility of the Results}

No significant differences were seen regarding duration of activity, $\mathrm{SpO}_{2}, \mathrm{VO}_{2}$, energy expenditure, MET, or total energy cost of activity during the control period in group B patients which ensured the repeatability of the measurements (Table 2). 
Fig. 3. Frequency of activities of daily living chosen by the patients, stratified for gender.

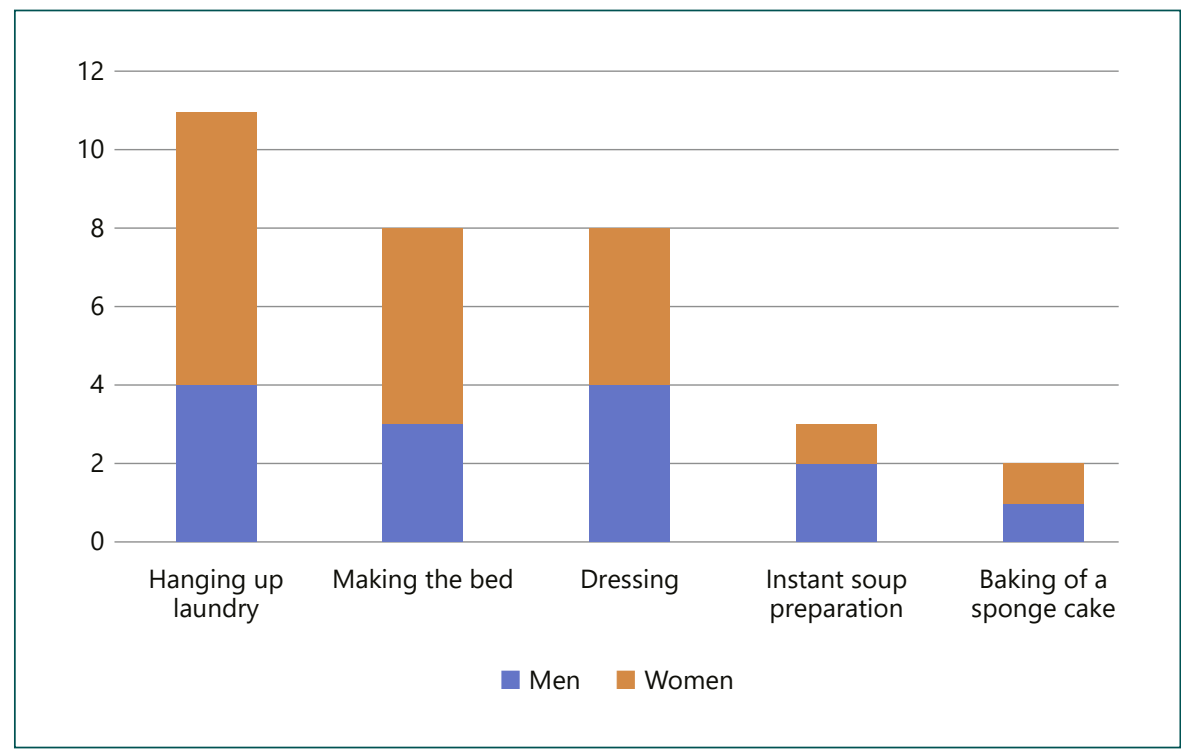

Table 3. Results from the Oxycon ${ }^{\mathrm{TM}}$ Mobile system, intervention period

\begin{tabular}{lccc}
\hline & $\begin{array}{l}\text { Before intervention } \\
(n=32)\end{array}$ & $\begin{array}{l}\text { After intervention } \\
(n=32)\end{array}$ & $\begin{array}{l}\text { Mean difference } \\
\text { (95\% confidence interval) }\end{array}$ \\
\hline Duration of activity, min & $6.0 \pm 3.9$ & $6.7 \pm 4.0$ & $0.7(-0.6,2.0)$ \\
$\mathrm{SpO}_{2}, \%$ & $89.7 \pm 5.2$ & $91.1 \pm 5.5^{*}$ & $1.4(0.04,2.8)$ \\
$\mathrm{VO}_{2}, \mathrm{~mL} / \mathrm{min}$ & $567 \pm 170$ & $538 \pm 167$ & $-29(-78,20)$ \\
Energy expenditure, kJ/min & $11.3 \pm 3.7$ & $10.5 \pm 3.5$ & $-0.8(-1.9,0.2)$ \\
$\mathrm{MET}$ & $2.3 \pm 0.6$ & $2.1 \pm 0.5^{*}$ & $-0.2(-0.3,-0.03)$ \\
Total energy cost of activity, kJ & $70.0 \pm 66.0$ & $71.7 \pm 55.2$ & $1.7(-15,18)$ \\
\hline
\end{tabular}

Values are presented as mean \pm SD. MET, metabolic equivalent of task. ${ }^{*} p<0.05$

\section{Results after the Intervention}

After the training period, the patients had a trend towards reduced absolute energy expenditure $(\mathrm{kJ} / \mathrm{min})$ and oxygen uptake $(\mathrm{mL} / \mathrm{min})$ for a given task, and a significant reduction in MET for the given task. In addition, the patients performed the task with less desaturation and without any significant increase in the time spent on the activity (Table 3 ).

\section{Discussion}

The main finding of the current study is that a 2-week training period concerning ECTs successfully reduces the energy spent on performing a relevant $\mathrm{ADL}$ in patients with symptomatic COPD, without significantly increas- ing the time spent on this activity. In addition, after training, less desaturation was seen while performing the activity. The results are in line with those of Velloso and Jardim $[6,12]$, who demonstrated that patients with COPD had a significantly lower oxygen uptake and dyspnea perception when using ECTs. In addition, Silva et al. [13] demonstrated that simple ECTs can prevent the occurrence of dynamic hyperinflation during the performance of ADL. Vaes et al. [14] recently showed that a comprehensive pulmonary rehabilitation program including ECTs can improve the performance of ADL by patients with COPD, indicated by a significantly shorter time to perform ADL and a lower oxygen uptake and dyspnea sensation.

The present study adds to this knowledge that specific training of patients in pace, activity performing tech- 
nique, and breathing technique successfully reduces the MET for a specific task, without guidance during the performance of the test and without any further intervention. In addition, it might be of relevance that a specific task is associated with less desaturation when performed using ECTs.

These results are specifically relevant to patients with COPD, who are burdened with a high symptom load that considerably affects their quality of life and daily functioning. Increasing autonomy and self-efficacy are key goals in the management of COPD and have a major impact on quality of life. A considerable amount of energy can be saved in daily life if a patient is able to save energy in performing an activity for $6 \mathrm{~min}$ and consistently uses the technique throughout the day. In addition, it has been shown that if subjects have learned the technique properly with one activity, this can be transferred to other activities. Indeed, supplied with a strategy for handling breathlessness, patients possibly feel more secure and less stressed. The new way to perform an activity also could lead to resuming and maintaining ADL [15].

Two strengths of this study are its randomized crossover design and the inclusion of a control period. No difference was seen between before and after the control period, which strengthens the conclusion that the differences noted between before and after the intervention were caused by the intervention. Another strength is the systematic repeated measurement of gas exchange and energy expenditure. Although the Oxycon Mobile system might underestimate $\mathrm{VO}_{2}$ at high workloads [16], the intensity of the activities in the current study was far from high. Furthermore, the Oxycon Mobile device has been shown to be reliable for determination of $\mathrm{VO}_{2}, \mathrm{VCO}_{2}$, and VE during a constant work rate test at $100 \mathrm{~W}$ in healthy subjects, with consistency and reliability of measurements [17]. This is in line with the findings by Rosdahl et al. [18], who compared the Oxycon Mobile with the Douglas Bag method.

Further strengths are the selection of activities by the patients based on personal relevance, the development of task-specific ECTs, and finally the focus on training of the ECT related to the activity.

Limitations of the study are the relatively high rate of dropout from the study, which is probably related to the complexity of the study population. However, similar dropout rates have previously been reported [14].

Subjects with malignant disease, clinically relevant chronic heart failure, or muscle, metabolic or renal disease were excluded from participation, but other comorbidities like anxiety could have influenced the results.
Nevertheless, the patients were their own controls, and the control group confirmed the repeatability and validity of the results. If ECT training influences symptoms of anxiety and depression and, consequently, influences the MET for a given task, then this should be considered as a part of the outcome [19].

No self-perceived evaluation of the use of ECTs has been described in this study, nor wellbeing afterwards in relation to COPD symptoms or health-related quality-oflife measures. Perceptions of patients' sensation when performing an activity have previously been evaluated with the Canadian Occupational Performance Measure (COPM), with positive results [14].

Another limitation of this study is that there might be a bias related to differences between the intervention and the control group, given the nonblinded design. A singleblinded intervention on the side of the investigator could have been a possibility. However, we aimed to reduce this effect as much as possible by separating the training and the assessment occupational therapist. Indeed, the occupational therapist who had trained the patient was never the same occupational therapist that performed the outcome measurements.

No proper power calculation was performed because of the exploratory character of the study. Nevertheless, we did evaluate the study by Velloso and Jardim [6] in which they were able to show a significant reduction in energy cost using ECTs in 16 male subjects. Therefore, we aimed to include at least 16 subjects in the intervention groups (17 in the study). In addition, we added a delayed intervention to the control group, which resulted in 32 subjects that received the intervention. Thus, it is safe to conclude that our study has been powered sufficiently.

The values presented are mean values for the 32 subjects. No analyses have been made on an individual level, but it is worth noting that some individual results deviate from the expected ones. This suggests a need to further individualize ECTs. Repetitive training occasions are necessary if persons should be able to change the way in which they perform activities [7]. A crucial point for obtaining positive results is supervision and motivation for change in performing activities. As COPD is a chronic and heterogeneous disease, the optimal moment for starting ECT training probably needs to be individualized. ECT is a well-known intervention for occupational therapists; the method is used for different kinds of diseases.

The Oxycon Mobile system has been used in single measurements before, in studies with persons having COPD [20-22]. The Oxycon Mobile device has also been used to assess the relationship between patients with car- 
diopulmonary disease and those with COPD when performing tests [23].

To our knowledge, the effect of ECTs on patients with COPD has not been measured by energy expenditure based on objective gas exchange measurement in a testintervention-retest way before. We have provided further evidence that teaching and training ECTs specific to predefined relevant ADL are effective for patients suffering from COPD, since a lower MET is noted with less desaturation for a given task but without a significantly longer time spent on the activity.

\section{Conclusions}

Patients with COPD can be successfully trained to use ECTs in an effective and energy-saving way in performing specific ADL relevant to the patients. Highlighting the use of different techniques for saving energy designed for each person and activity is desirable.

\section{Acknowledgements}

The authors would like to thank all informants for participating in the study and for all time they spent with both training and transportation to the occupational therapy ward. The authors would also like to acknowledge financial support from the "Agreement concerning research and education of doctors" (ALF agreement), the Swedish Heart-Lung Foundation, and the Local Re- search and Development Board for Gothenburg and Södra Bohuslän. The authors would also like to thank Dr. Mats Hemlin for inclusion of patients. L.E.G.W. Vanfleteren acknowledges grants from the Swedish state under the agreement between the Swedish government and the country councils, the ALF agreement, and grants from Familjen Kamprads Stiftelse.

\section{Statement of Ethics}

All patients provided informed consent. The study was approved by the Regional Ethics Board in Gothenburg (Dnr 190-06).

\section{Disclosure Statement}

A.S.L.W., C.G., S.L., and F.S. declare no conflicts of interest. L.E.G.W.V. reports personal fees from Boehringer Ingelheim, AstraZeneca, Chiesi, Novartis, PulmonX, Menarini and GlaxoSmithKline outside the submitted work.

\section{Author Contributions}

Authorship and contributorship: A.S.L.W., C.G., S.L., F.S., and L.E.G.W.V.; conception and design: A.S.L.W., C.G., S.L., and F.S.; drafting of the manuscript: A.S.L.W., C.G., F.S., and L.E.G.W.V.; acquisition and analysis of the data: A.S.L.W., C.G., and F.S.; analysis and interpretation of the data: A.S.L.W., C.G., F.S., and L.E.G.W.V.; drafting of the manuscript for important intellectual content: A.S.L.W., C.G., S.L., F.S., and L.E.G.W.V. All coauthors critically revised the article and gave final approval for this version to be published.

\section{References}

1 Lorenzi CM, Cilione C, Rizzardi R, Furino V, Bellantone T, Lugli D, et al. Occupational therapy and pulmonary rehabilitation of disabled COPD patients. Respiration. 2004 MayJun;71(3):246-51.

2 Norweg A, Bose P, Snow G, Berkowitz ME. A pilot study of a pulmonary rehabilitation programme evaluated by four adults with chronic obstructive pulmonary disease. Occup Ther Int. 2008;15(2):114-32.

3 Brooke M. COPD and its management in Australia. JARNA. 2013;16(2):8-12.

4 Dreiling D. Energy conservation. Home Health Care Manage Pract. 2009;22(1):26-33.

5 Carson D. Energy conservation: achieving a balance of work, rest and play. Toronto, Canada: COTA Health; 2002.

6 Velloso M, Jardim JR. Study of energy expenditure during activities of daily living using and not using body position recommended by energy conservation techniques in patients with COPD. Chest. 2006 Jul;130(1):126-32.
7 Hansen FB, Meningshoel AM. Effekt of ADLtrening for personer med kronisk obstruktiv lungesykdom. Ergoterapeuten Norway. 2011; 3:38-46.

8 Fernandes M, Cukier A, Feltrim MI. Efficacy of diaphragmatic breathing in patients with chronic obstructive pulmonary disease. Chron Respir Dis. 2011;8(4):237-44.

9 Migliore A. Management of dyspnea guidelines for practice for adults with chronic obstructive pulmonary disease. Occup Ther Health Care. 2004;18(3):1-20.

10 Weir JB. New methods for calculating metabolic rate with special reference to protein metabolism. J Physiol. 1949 Aug;109(1-2):19.

11 Ainsworth BE, Haskell WL, Whitt MC, Irwin ML, Swartz AM, Strath SJ, et al. Compendium of physical activities: an update of activity codes and MET intensities. Med Sci Sports Exerc. 2000 Sep;32(9 Suppl):S498-504.
12 Velloso M, Jardim JR. Functionality of patients with chronic obstructive pulmonary disease: energy conservation techniques. J Bras Pneumol. 2006 Nov-Dec;32(6):580-6.

13 Silva CS, Nogueira FR, Porto EF, Gazzotti MR, Nascimento OA, Camelier A, et al. Dynamic hyperinflation during activities of daily living in COPD patients. Chron Respir Dis. 2015 Aug;12(3):189-96.

14 Vaes AW, Delbressine R, Mesquita R, Goertz YM, Janssen DJ, Nakken N, et al. The impact of pulmonary rehabilitation on activities of daily living in patients with chronic obstructive pulmonary disease. J Appl Physiol (1985). 2019 Mar;126(3):607-15.

15 Maiste E, Karlsson U. Effekten av den arbetsterapeutiska interventionens påverkan på utförandet av vardagliga aktiviteter bland personer med diagnosen kronisk obstruktiv lungsjukdom - en intervjustudie. Göteborg: Göteborgs Universitet; 2009. 
16 Perret C, Mueller G. Validation of a new portable ergospirometric device (Oxycon Mobile) during exercise. Int J Sports Med. 2006 May;27(5):363-7.

17 Akkermans MA, Sillen MJ, Wouters EF, Spruit MA. Validation of the Oxycon Mobile metabolic system in healthy subjects. J Sports Sci Med. 2012 Mar;11(1):182-3.

18 Rosdahl H, Gullstrand L, Salier-Eriksson J, Johansson P, Schantz P. Evaluation of the Oxycon Mobile metabolic system against the Douglas Bag method. Eur J Appl Physiol. 2010 May;109(2):159-71.
19 Jany BH, Bals R, Buhr-Schinner H, Dreher M, Koczulla AR, Jany L, et al. COPD: rethinking patient management - how to approach a challenging patient group successfully. Respiration. 2019;97(4):363-8.

20 Vaes AW, Wouters EF, Franssen FM, UszkoLencer NH, Stakenborg KH, Westra M, et al. Task-related oxygen uptake during domestic activities of daily life in patients with COPD and healthy elderly subjects. Chest. 2011 Oct; 140(4):970-9.

21 Hannink JD, van Helvoort HA, Dekhuijzen PN, Heijdra YF. Dynamic hyperinflation during daily activities: does COPD Global Initiative for Chronic Obstructive Lung Disease stage matter? Chest. 2010 May;137(5):116121.
22 Lahaije AJ, van Helvoort HA, Dekhuijzen PN, Heijdra YF. Physiologic limitations during daily life activities in COPD patients. Respir Med. 2010 Aug;104(8):1152-9.

23 Vonbank K, Marzluf B, Knötig M, Funk GC. Agreement between cardiopulmonary exercise test and modified 6-min walk test in determining oxygen uptake in COPD patients with different severity stages. Respiration. 2020 [Epub ahead of print].

24 Global Intiative for Chronic Obstructive Lung Disease (GOLD). Global strategy for the diagnosis, management, and prevention of COPD. 2019. Available from: http://www. goldcopd.org/. 